\title{
Flow-cytometry analysis reveals persister resuscitation characteristics
}

\author{
Sayed Golam Mohiuddin, Pouria Kavousi and Mehmet A. Orman ${ }^{*}$
}

\begin{abstract}
Background: Persisters and viable but non-culturable (VBNC) cells are two phenotypic variants known to be highly tolerant to antibiotics. Although both cell types are stained as live and often appear as nongrowing during antibiotic treatment, the only distinguishing feature is the ability of persisters to recolonize in standard culture media in the absence of antibiotics. Despite considerable progress in the characterization of persister formation mechanisms, their resuscitation mechanisms remain unclear due to technical limitations in detecting and isolating these cell types in culture environments that are highly heterogeneous.

Results: In this study, we used a methodology integrating flow cytometry, fluorescent protein expression systems and ampicillin-mediated cell lysing technique to monitor persister resuscitation at the single-cell level. With this method, we were able to investigate the effects of various culture conditions (e.g., antibiotic treatment time, the length of the stationary phase in overnight pre-cultures, or pretreatment of cells with a metabolic inhibitor) on persister resuscitation. Although we observed long-term pre-cultures have many more VBNC cells compared to short-term pre-cultures, only a small fraction of non-lysed cells was able to resuscitate in all conditions tested. Regardless of pre-culturing and ampicillin treatment times, these persister cells started to resuscitate within 1 hour, after they were transferred to fresh liquid media, with the same doubling time that normal cells have. Our analysis further showed that ampicillin was not able to lyse the cells in the presence of arsenate, a metabolic inhibitor commonly used to increase bacterial persistence. However, the removal of arsenate during antibiotic treatment resulted in cell lysis and a reduction in persister levels despite the significant decrease in ATP levels in the cells.

Conclusions: The strategy presented in this study helps us monitor persister resuscitation at the single-cell level, and simultaneously quantify persister, VBNC and dead cell subpopulations in ampicillin-treated cultures. Our results indicate that the characterization of persister resuscitation with flow cytometry will enhance the current molecularlevel understanding of persistence and its evolution.
\end{abstract}

Keywords: Escherichia coli, Flow cytometry, Persister resuscitation, Viable but non-culturable cells, ATP depletion, Beta-lactams, Fluorescent proteins, Single-cell analysis, Arsenate pretreatment

\footnotetext{
* Correspondence: morman@central.uh.edu

Department of Chemical and Biomolecular Engineering, University of Houston, S222 Engineering Bldg 1, 4726 Calhoun Rd, Houston, TX 77204, USA
}

(c) The Author(s). 2020 Open Access This article is licensed under a Creative Commons Attribution 4.0 International License, which permits use, sharing, adaptation, distribution and reproduction in any medium or format, as long as you give appropriate credit to the original author(s) and the source, provide a link to the Creative Commons licence, and indicate if changes were made. The images or other third party material in this article are included in the article's Creative Commons licence, unless indicated otherwise in a credit line to the material. If material is not included in the article's Creative Commons licence and your intended use is not permitted by statutory regulation or exceeds the permitted use, you will need to obtain permission directly from the copyright holder. To view a copy of this licence, visit http://creativecommons.org/licenses/by/4.0/ The Creative Commons Public Domain Dedication waiver (http://creativecommons.org/publicdomain/zero/1.0/) applies to the data made available in this article, unless otherwise stated in a credit line to the data. 


\section{Background}

Persistence is a non-genetic and non-heritable bethedging strategy that has evolved in many prokaryotic and eukaryotic cell types [1]. It results from a phenotypic switch from a normal, growing state to a tolerant, nongrowing state. Environmental heterogeneity is thought to produce selection pressures that maintain the persister phenotypes. Both stochastic processes and deterministic factors, pertaining to stress responses, cell age, quorum sensing and toxin/antitoxin systems, are known to facilitate persister formation [1-4]. Regardless of the extended periods of latency, persister cells have the ability to exit from the persistence state and establish heterogeneous cell populations.

Despite the considerable progress in the characterization of persister formation mechanisms, the physiology of these phenotypic variants remains unclear. The assumption that persisters are globally dormant cells $[5,6]$ has discouraged many scientists from characterizing their physiology. Moreover, direct assessments of persister physiology using conventional approaches, such as mass spectrometry or transcriptomic profiling, are currently hindered by limitations in the isolation procedures. Despite their notable contributions to persister research, existing strategies [7-11] often yield samples that are enriched in persisters but are highly contaminated with other cell types, such as viable but non-culturable cells (VBNCs), which are generally more abundant than persisters $(\sim 2$-log-fold more) $[8,9]$. Although persister and VBNC cells are concurrently present in cell cultures, appear as non-growing and stay alive during antibiotic treatments, the only distinguishing feature is the ability of persisters to recolonize in standard culture media in the absence of antibiotics whereas the resuscitation of VBNCs on such media is rarely possible [12, 13]. However, certain environments, such as plating on media with the antioxidants and catalases, have been shown to restore VBNC cell culturability [14]. It is possible that persistence represents a transitory phase leading to the VBNC state and contributes to the accumulation of VBNC cells due to the accumulation of stress-induced intracellular damage.

The phenotypic features that allow persister resuscitation, a hallmark of persistence, remain relatively unexplored; we still don't know what mechanisms trigger these phenotypic variants to exit from the persistent state, to repopulate upon cessation of antibiotic treatment, and to regain antimicrobial sensitivity. Unfortunately, detecting and isolating resuscitating persisters in antibiotic-treated cultures is challenging due to their low abundance in a highly heterogeneous environment that also contains dead cells, debris, and VBNC cells [12]. Here, we have overcome these technical limitations by using a methodology that integrates various techniques (e.g., cell division and antibiotic tolerance assays, and flow cytometry analysis) in a tailored approach. This method, which has enabled us to monitor persister resuscitation as well as quantify the persister- and VBNCcell fractions, will enhance our current understanding of persister resuscitation processes.

\section{Results}

Monitoring the resuscitating cells with the proteindilution method

One of the common persister-isolation techniques involves treating cultures with beta-lactams (such as ampicillin) and sedimentation of the non-lysed cell population [10]. Ampicillin inhibits transpeptidase enzymes involved in bacterial cell wall synthesis, thus targeting proliferating cells only $[15,16]$. This was also verified by a fluorescent protein-dilution method here (Fig. 1), a strategy commonly used to monitor cell growth $[3,9]$. In this method, we first induced $m$ Cherry expression during overnight growth of an E. coli strain that harbors a chromosomally integrated IPTG-inducible mCherry expression cassette. The mCherry-positive cells from the overnight pre-culture (Fig. $1, \mathrm{t}=0$ ) were then inoculated into a fresh medium without the inducer. At time zero, all cells exhibited a high level of mCherry (red) fluorescence, which declined as the cells divided, except in a small subpopulation $(\sim 4 \%$ of the entire population at $\mathrm{t}=150 \mathrm{~min}, \mathrm{OD}_{600}=0.25$ ) whose fluorescence remained constant due to the lack of division (Fig. 1, subpopulations highlighted with red circles). As expected, the growing cells, exhibiting higher forward scatter (FSC) signals, became filamented and were lysed rapidly upon exposed to ampicillin; however, the nongrowing cell population, which was shown to be enriched with persister and $\mathrm{VBNC}$ cells $[8,12]$, remained intact (Fig. 1).

Using the protein dilution and ampicillin-induced cell lysing techniques, we wanted to monitor persister resuscitation on flow-cytometry diagrams. Unlike the strategy described above, IPTG was kept in the media during the exponential growth phase and ampicillin treatment. Although persisters are largely assumed to be pre-existing non-growing cells, antibiotics are also known to induce cell dormancy and persistence in proliferating cells [17]. In fact, up to $20 \%$ of persister cells can arise from growing cell subpopulations [8]. Therefore, IPTG was used to maintain high fluorescent signals in these persister types. When we treated the mid-exponential-phase cells $\left(\mathrm{OD}_{600}=0.25\right.$, Fig. $\left.2 \mathrm{a}\right)$ with ampicillin, the growing cells eventually lost their membrane integrity and mCherry (Fig. $2 \mathrm{a}, \mathrm{t}=10$ to $180 \mathrm{~min}$ ), as expected. In contrast, live, intact cells, comprising persister and VBNC cells, retained high fluorescence (Fig. 2a, $\mathrm{t}=180 \mathrm{~min}$, the subpopulation highlighted with a red circle). Our flow cytometry images showed that a $3-\mathrm{h}$ treatment is 


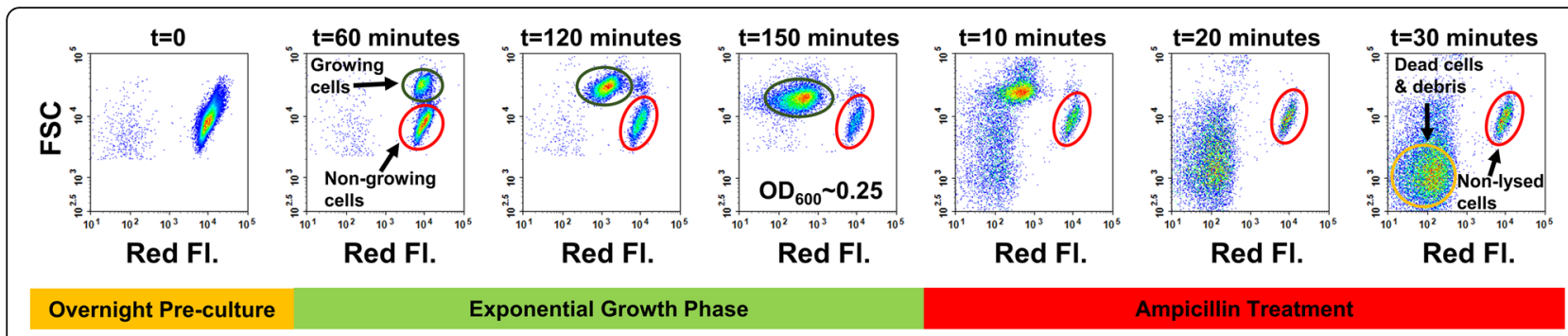

Fig. 1 Isolating non-growing cell subpopulations with ampicillin-induced cell lysing and protein-dilution methods. mCherry positive cells from overnight ( $24 \mathrm{~h}$ ) pre-cultures were diluted 100-fold in fresh LB broth without IPTG. Upon reaching the exponential-growth phase $\left(\mathrm{OD}_{600}=0.25\right)$, cells were treated with ampicillin at 10X MIC concentration $(60 \mu \mathrm{g} / \mathrm{ml})$. Growing cell, non-growing cell and dead-cell/debris subpopulations are highlighted with dark green, red and orange circles, respectively. Red Fl.: Red Fluorescence

sufficient to lyse all antibiotic sensitive cells (Fig. 2a, $\mathrm{t}=$ $180 \mathrm{~min}$ ). This treatment length was also found to be sufficient to obtain a bi-phasic kill curve of colonyforming unit (CFU) counts, which ensures the enrichment of persisters and the death of non-persister cells in the cultures (Fig. 2c). After the treatment, cells were washed to remove the antibiotic and IPTG, and then transferred to fresh Luria-Bertani (LB) broth to stimulate persister resuscitation. Persisters, unlike VBNCs, can exit from their non-proliferating phenotypic state and

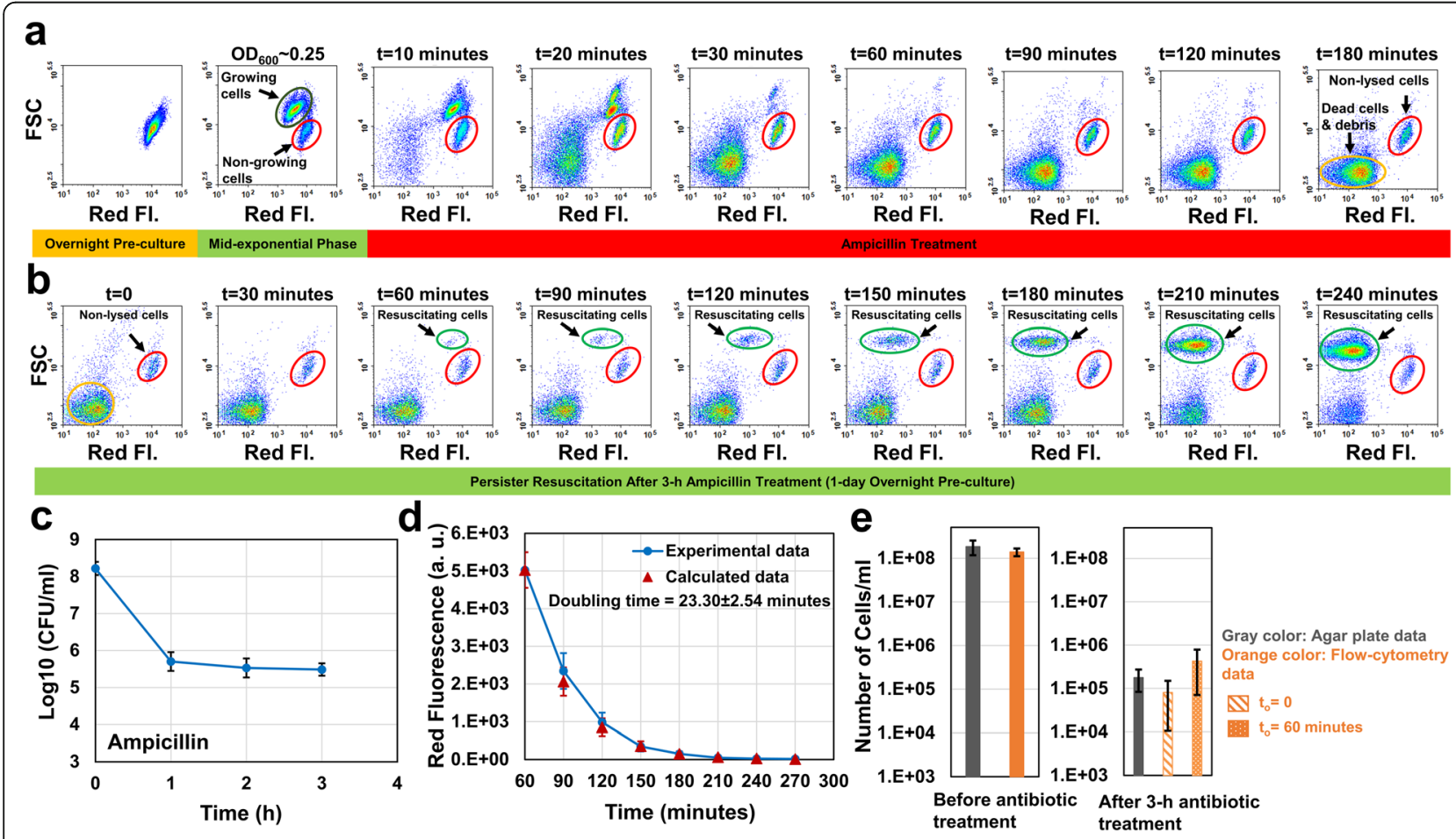

Fig. 2 Monitoring persister resuscitation. a Exponential-phase cells at $\mathrm{OD}_{600}=0.25$ (prepared from 1-day overnight pre-cultures) were treated with $60 \mathrm{\mu g} / \mathrm{ml}$ ampicillin for $3 \mathrm{~h}$ in the presence of IPTG. Cells during the treatment were collected at designated time points and analyzed by a flow cytometer. b After 3-h ampicillin treatments, cells were collected and washed to remove the antibiotic and the inducer. The cells were then resuspended into fresh LB broth and cultured. At designated time points, samples were collected to be analyzed with a flow cytometer to monitor persister resuscitation $(\mathrm{N}=4)$. c Cells during the antibiotic treatment were plated on agar media at designated time points for $\mathrm{CFU}$ enumeration $(N=4)$. $\mathbf{d}$ The doubling time of the resuscitating cells was calculated using the decay equation (see the Materials and Methods) and the mean red fluorescence intensities of dividing cells (highlighted with light green circles) $(N=4)$. e Resuscitating cell levels (number of cells per $1 \mathrm{ml}$ culture medium) after 3-h antibiotic treatments were estimated from the standard agar plating method (gray column) and the flowcytometry analysis (assuming $\mathrm{t}_{\mathrm{o}}=0$ and $\mathrm{t}_{\mathrm{o}}=60 \mathrm{~min}$; patterned orange columns). Cells were also counted before the antibiotic treatments. Growing, non-lysed, dead (debris) and resuscitating cell subpopulations are highlighted with dark green, red, orange and light green circles, respectively. The flow-cytometry diagrams are a representative replicate of four independent biological replicates. Error bars represent the standard deviations 
proliferate upon removal of antibiotics. The resuscitating cells were detected by monitoring single-cell mCherry levels using a flow cytometer. We observed that, although the surviving live cells initially exhibited high fluorescence, upon resuscitation in the absence of IPTG, flow cytometry revealed ongoing cell division as the dilution of mCherry protein (Fig. 2b, subpopulations highlighted with green circles). Forward scatter was also expected to increase due to the elongation characteristic of the growing cells. The fluorescence of the cells that did not resuscitate (i.e., VBNCs) remained constant due to lack of cell division (Fig. 2b, subpopulations highlighted with red circles).

\section{Ampicillin persisters wakeup within one hour}

Our flow-cytometry data indicates that persister cells started to resuscitate within 1 hour upon their transfer to fresh media (Fig. 2b). We observed a similar trend in the control cultures where stationary-phase cells from overnight pre-cultures were transferred to fresh media without receiving antibiotic treatments. These untreated cells also started to divide within 1 hour (Additional file 1: Fig. S1A). The doubling time of resuscitating persisters (estimated from the fluorescence decay equation; see Methods) was obtained as $23.30 \pm 2.54 \mathrm{~min}$ (Fig. 2d), which was found to be consistent with the doubling time of normal, untreated cells $(23.91 \pm 1.7 \mathrm{~min})$ that grew in LB (Additional file 1: Fig. S1B). We also estimated the initial number of persister cells $\left(\mathrm{N}_{\mathrm{o}}\right)$ that woke up in fresh liquid cultures, using the classical exponentialgrowth equation, $N=N_{o} 2^{\left(t-t_{o}\right) / t_{d}}$, where $t_{\mathrm{d}}$ is the doubling time (calculated from the fluorescence decay equation) and $\mathrm{N}$ is the number of resuscitated cells at time $\mathrm{t}$. For $\mathrm{N}$, we used the flow cytometry cell counts obtained at $t=240 \mathrm{~min}$ (Fig. 2b, highlighted with a green circle). Although it is hard to predict the exact initial resuscitation time $\left(t_{\mathrm{o}}\right)$ of persister cells, our flow-cytometry diagrams showed that these cell subpopulations became visible at $\mathrm{t}=60 \mathrm{~min}$ (Fig. 2b, highlighted with a green circle), indicating that their wake-up time $\left(t_{o}\right)$ should be less than $60 \mathrm{~min}$. The same trend was also observed during the wake-up of untreated, stationary phase cells (Additional file 1: Fig. S1A). Here, we used two scenarios to calculate the $\mathrm{N}_{\mathrm{o}}$ levels from the flow-cytometry diagrams: (i) assuming $t_{o}=0$, a scenario that underestimates $\mathrm{N}_{\mathrm{o}}$ levels since resuscitation is not expected to happen at this time point, or (ii) assuming $t_{o}=60 \mathrm{~min}$, a scenario that overestimates $\mathrm{N}_{\mathrm{o}}$ levels since persister cells have already resuscitated (Fig. 2e, patterned orange columns). The actual $\mathrm{N}_{\mathrm{o}}$ should be between these two calculated values. Since the resuscitating cells at 60 min were measurable by the flow cytometer, we compared the calculated cell levels at $t_{o}=60 \mathrm{~min}$ with the experimentally determined values to further validate our computational analysis. As expected, we did not see a significant difference between the calculated and experimental data (Additional file 1: Fig. S2A). We also quantify $\mathrm{N}_{\mathrm{o}}$ levels using the standard agar plating method; briefly, samples after ampicillin treatments were collected, washed to dilute antibiotics to sub-MIC levels, and plated on agar plates. Once a persister cell starts dividing, it forms a colony; thus, the CFU levels correlate with the number of resuscitating cells on agar plates. $\mathrm{N}_{\mathrm{o}}$ estimates from the flow-cytometry analysis and the CFU measurements of agar plates were found to be consistent and within the expected range (Fig. 2e). Still, resuscitating cells, as measured by CFUs, were calculated as $\sim 4 \%$ of the nonlysed cell subpopulation. The remaining, 96\% cells, classified as VBNCs, did not resume replication. Consistent with the previously published results $[8,9,12]$, VBNC cells were found to be more abundant than persisters in our cultures as well. We note that the dilution of mCherry in resuscitating cells is not due to the protein leakage caused by compromised membranes. In order to verify that these cells are alive, we used a pQE$80 \mathrm{~L}$ expression system, enabling us to tightly regulate the expression of a green fluorescent protein (GFP) with IPTG. Unlike the mCherry-dilution method, GFP was not induced initially. Cells were first treated with ampicillin for $3 \mathrm{~h}$ in the absence of the inducer, and then, transferred to fresh media with IPTG. As expected, a similar fraction of cell subpopulation started to resuscitate and overexpress GFP (Additional file 1: Fig. $\mathrm{S} 3 \mathrm{ABC}$ ), verifying that resuscitating cells are live cells with active metabolic mechanisms.

\section{Long-term ampicillin treatment did not affect the persister resuscitation and doubling time}

To elucidate the effect of long-term antibiotic treatments on persister resuscitation, we treated the midexponential-phase cells with ampicillin for $16 \mathrm{~h}$. Although, non-lysed cell levels quantified by flow cytometry in short- and long-term persister assay cultures (3-h treatment vs. 16-h treatment) were found to be similar (Fig. 3c), persister levels obtained from CFU measurements were slightly lower $(P<0.05)$ in 16 -h treatment cultures (Figs. 2e and 3d; gray columns representing the 3-h or 16-h ampicillin treatments). Since the slowerkilling phase in the biphasic kill curves is the hallmark of the persistence phenotype, it is possible that longer exposure to the antibiotic has killed more persister cells or converted some of them into VBNC cells. However, the observed increase in VBNC levels in the long-term persister assay cultures is not statistically significant (Additional file 1: Fig. S4), which may be expected considering that VBNCs are orders of magnitude more abundant than persisters. 


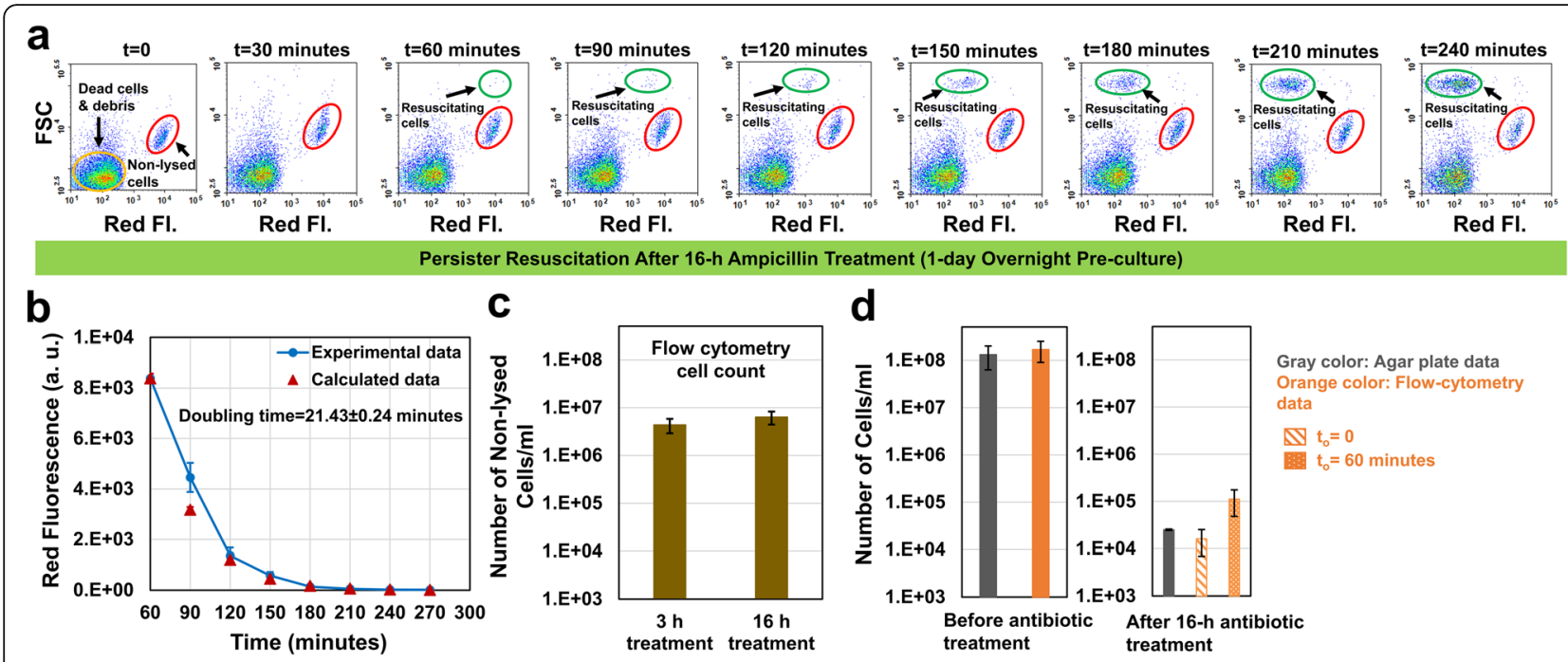

Fig. 3 Effect of long-term antibiotic treatment on persister resuscitation. a After 16-h ampicillin treatment, cells were transferred to fresh $L B$ broth to monitor persister resuscitation with a flow cytometer $(N=4)$. $\mathbf{b}$ The doubling time of the resuscitating cells $(N=4)$. c Comparison of non-lysed cell levels in short-term and long-term ampicillin treated cultures. Cells were counted with flow cytometry $(N=4)$. $\mathbf{d}$ Cell counts before antibiotic treatments and resuscitating cell levels after 16-h antibiotic treatments (estimated from agar plates or flow-cytometry analysis) $(N=4)$. Error bars represent the standard deviations

Persister cells similarly started to resuscitate in fresh LB broth within 60 min after the removal of antibiotics (Fig. 3a, $\mathrm{t}=60 \mathrm{~min}$, the subpopulation highlighted with a green circle) with a doubling time $(21.43 \pm 0.24)$ (Fig. $3 \mathrm{~b}$ ) similar to that of untreated cells (Additional file 1: Fig. S1B). CFU measurements from agar plates were found to be within the range of $\mathrm{N}_{\mathrm{o}}$ levels estimated from our flowcytometry analysis (Fig. 3d and Additional file 1: Fig. S2B), although persister cells still constitute a small fraction of the non-lysed cell subpopulation. Overall, these results unveiled that long-term treatments do not pose any impact on non-lysed cell levels as well as persister-wake up time or doubling time.

\section{Long-term pre-culturing enhances VBNC cell levels}

Persister cell populations are heterogeneous and exhibit diverse, but poorly characterized metabolic and gene expression activities. Whereas some persisters can arise from growing cell subpopulations [8], many persister cells are found to be at the non-proliferating state before antibiotic treatments, and they are largely formed by passage through the stationary phase [18]. To analyze the effects of stationary-phase lengths on persister resuscitation, we cultured the overnight pre-cultures up to 9 days. On certain days $(1,2,3,5,7$, and 9 days), cells from overnight pre-cultures were transferred to fresh media, cultured until they reached the mid-exponential growth phase $\left(\mathrm{OD}_{600}=0.25\right)$, and then treated with ampicillin for $3 \mathrm{~h}$ or $16 \mathrm{~h}$. Although our results clearly showed that long-term pre-culturing did not significantly impact the persister resuscitation and doubling time (Fig. 4a,b,d,e and Additional file 1: Fig. S5ABCD and Fig. S6ABCD), it significantly increased the nonlysed cell (VBNCs) levels (Fig. 4f,g). Approximately, 10\% percent of exponential phase cells obtained from 9-day overnight pre-cultures were not lysed by ampicillin (Fig. 4f,g). We note that mCherry levels of the non-lysed cells from long-term pre-cultures are lower than those from short-term pre-cultures (Figs. 2a vs. 4a); this is because of the increased mCherry protein degradation and/ or leakage in long-term pre-cultures (Additional file 1: Fig. S7), known characteristics of the late-stationary phase cells $[19,20]$. Interestingly, we observed a significant difference between persister levels obtained from flow-cytometry diagrams and CFU measurements (Fig. 4h,i and Additional file 1: Fig. S2CD). Our analysis indicates that at least 10fold more cells (based on $t_{o}=0$ estimates from flowcytometry analysis, Fig. 4h,i) resuscitated in liquid cultures compared to solid media. This interesting phenomenon, which has been observed in both 3-h- and 16-hampicillin-treated cultures (Fig. $4 \mathrm{~h}, \mathrm{i}$ ), indicates the importance of culture conditions to persister cell resuscitation.

Stationary-phase lengths in pre-cultures significantly affected the ability of persister cells to wake up in solid media. Persisters levels (as measured by CFU counts on agar plates) in long-term pre-cultures were found to be almost 50-fold less than those identified in short-term pre-cultures (Figs. 2c vs. 4c). However, this was not observed in liquid media. In fact, our flow cytometry analysis showed that a similar amount of persister cells started to wake up within 1 hour in liquid cultures, regardless of the pre-culturing lengths or ampicillin 


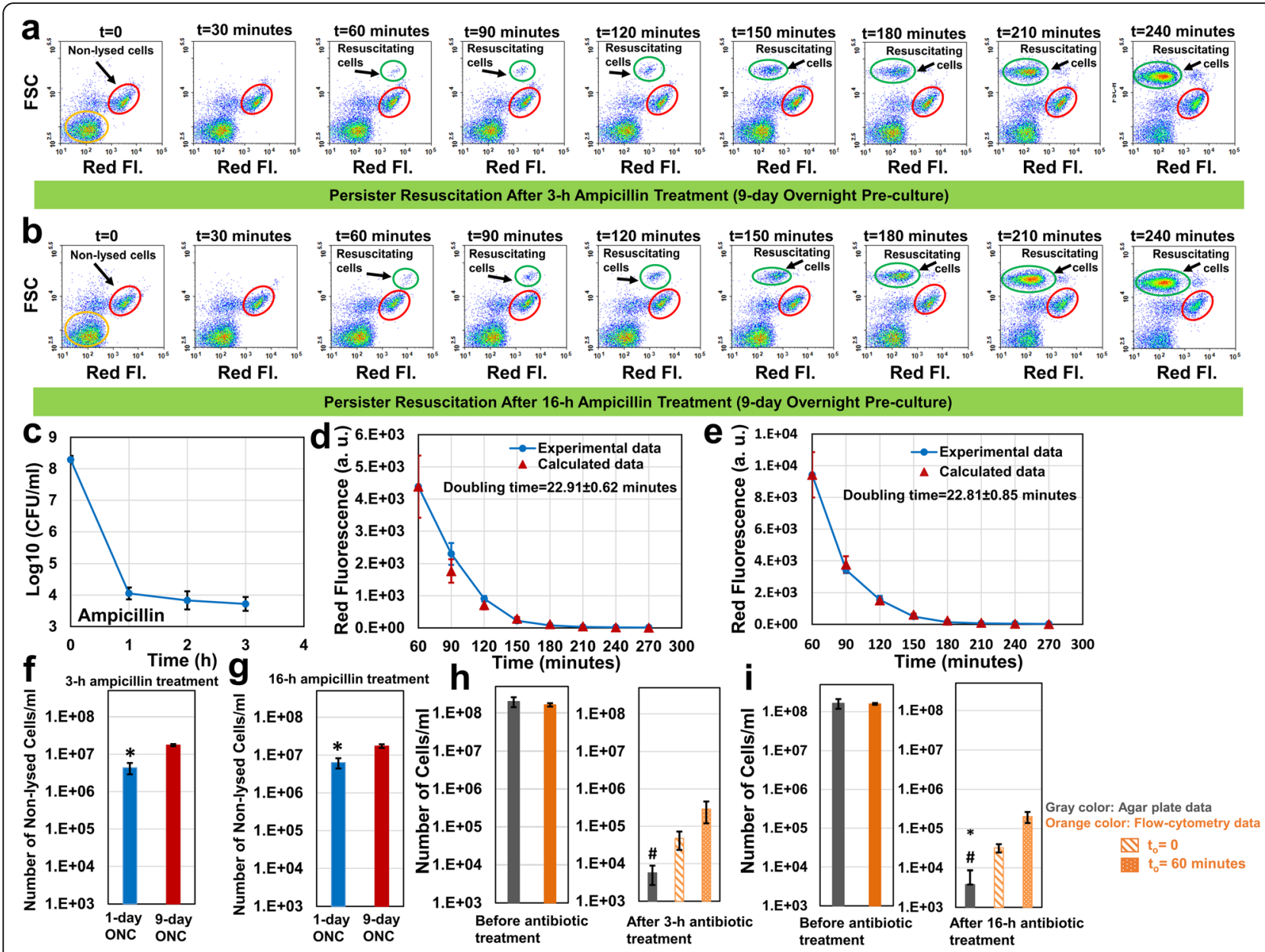

Fig. 4 The effect of long-term pre-culturing on persister resuscitation. $\mathbf{a}-\mathbf{b}$ Cells from 9-day overnight pre-cultures were inoculated in fresh media, cultured until $\mathrm{OD}_{600}=0.25$, and then treated with ampicillin for $3 \mathrm{~h}$ or $16 \mathrm{~h}$. After ampicillin treatments, cells were transferred to LB broth to monitor persister resuscitation with a flow-cytometry $(N=4)$. c Cells during the antibiotic treatments were plated to obtain the bi-phasic kill curve $(N=4)$. $\mathbf{d}$ The doubling time of the resuscitating cells after 3 -h ampicillin treatments $(N=4)$. e The doubling time of the resuscitating cells after 16-h ampicillin treatments $(N=4)$. $\mathbf{f - g}$ Comparison of non-lysed cell levels in short-term (1 day) and long-term (9 days) pre-cultures $(N=4)$. ${ }^{*}$ indicates a significant difference between short-term and long-term pre-cultures $(P<0.05)$. h-i Resuscitating cell levels after 3-and 16-h antibiotic treatments $(N=4)$. * indicates a significant difference between flow-cytometry $\left(t_{0}=0\right)$ and agar plate cell counts $(P<0.05)$. \# indicates a significant difference between flow-cytometry $\left(t_{0}=60 \mathrm{~min}\right)$ and agar plate cell counts $(P<0.05)$. Error bars represent the standard deviations. ONC:

Overnight pre-culture

treatment times (persister data highlighted with patterned orange columns in Figs. 2e, 3d and 4hi). The cell growth profiles of the resuscitating cells in liquid cultures were also found to be very similar in all conditions tested (Fig. 5). Doubling times obtained from these growth profiles (Fig. 5) were found to be consistent with those obtained from mCherry-dilution method (Additional file 1: Table S1). Overall, these results indicate that although long-term culturing does not significantly affect the persister resuscitation and doubling time in liquid cultures, it impacts the non-lysed cell levels. Our study also clearly shows that the culture environment affects the ability of non-lysed cells to wake-up.

\section{Ampicillin cannot lyse the pre-proliferating cells in the presence of arsenate}

A correlation between ATP depletion and persistence has been consistently shown in previous studies using arsenate-treated cell cultures [21-23]. Arsenate, which competes with phosphate [24], is thought to increase persistence in bacteria by reducing ATP production [21, 22]. To elucidate the resuscitation characteristics of cell populations exhibiting increased persistence, we treated the exponential-phase cultures $\left(t=150 \mathrm{~min}, \quad \mathrm{OD}_{600}=0.25\right)$ with $10 \mathrm{mM}$ arsenate for $30 \mathrm{~min}$ followed by ampicillin treatment with arsenate (co-treatment), as described previously $[21,22]$. Thirty-min pretreatment was found to be sufficient to inhibit cell proliferation (Fig. 6b, the cell 


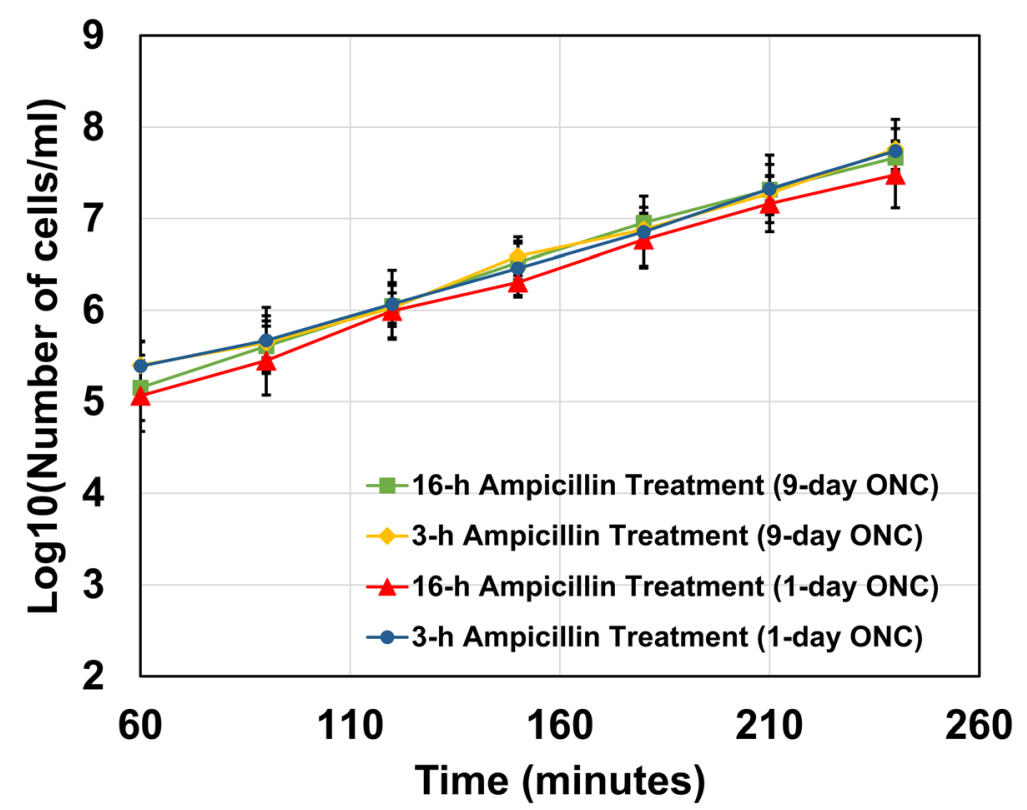

Fig. 5 Growth curves of resuscitating cells in liquid cultures. The number of resuscitating cells at indicated time points was quantified with a flow cytometer $(N=4)$. Error bars represent the standard deviations. ONC: Overnight pre-culture
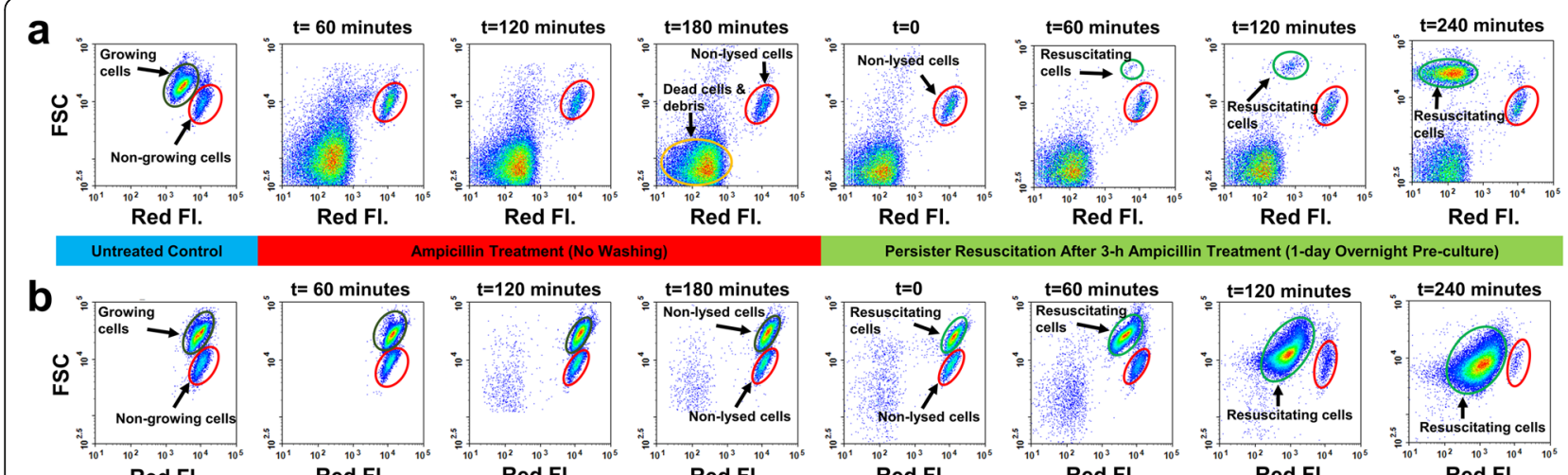

Persister
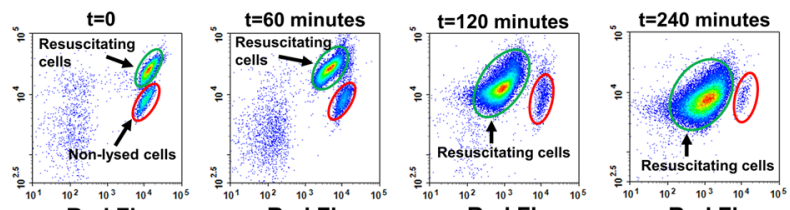

After Arsenate Treatment

$$
\text { Red FI. }
$$

Red FI.

Red FI.

Red Fl.

Red FI.
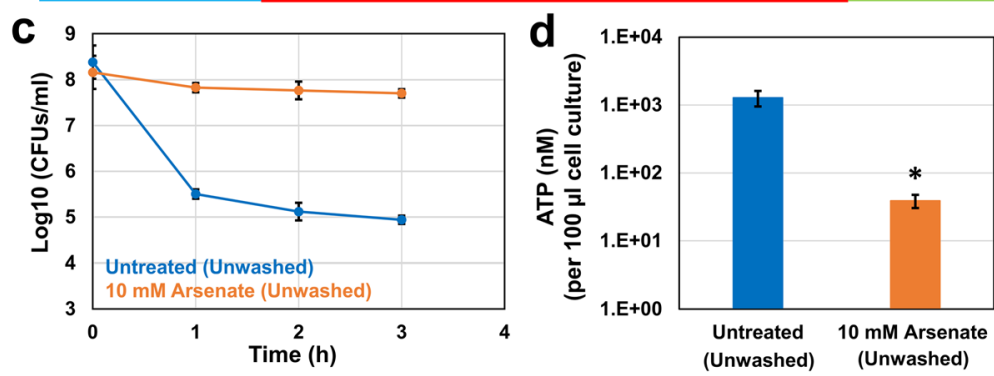

Fig. 6 The effects of arsenate and ampicillin co-treatment on persister formation, ATP levels, and persister resuscitation. a-b Exponentially growing cells $\left(\mathrm{OD}_{600}=0.25\right)$ were treated with solvent (DI water) or $10 \mathrm{mM}$ arsenate for $30 \mathrm{~min}$. At $\mathrm{t}=180 \mathrm{~min}$, ampicillin was added into cell cultures. After the ampicillin treatment, cells were transferred to fresh LB media to monitor persister resuscitation with a flow cytometry. c Cells during the antibiotic treatments were plated to generate the kill curves $(N=3)$. $\mathbf{d}$ ATP levels of control and co-treatment groups were measured

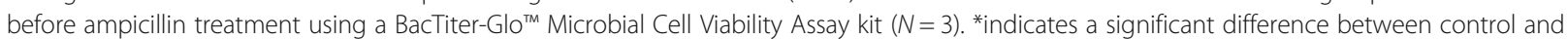
co-treatment groups $(P<0.05)$ 
subpopulations highlighted with dark-green circles) and to reduce ATP levels (Fig. 6d), consistent with the studies published by Kim Lewis' group [21-23]. As expected, the persister levels of arsenate-treated cultures were significantly higher than those of the control groups (Fig. 6c). However, our flow cytometry analysis indicates that this increase in persistence may be due to the bacteriostatic effect of arsenate during antibiotic treatment, as ampicillin was not able to lyse the pre-proliferating cells in the presence of arsenate (Fig. 6b, the cell subpopulations highlighted with dark-green circles). Interestingly, all these non-lysed, pre-proliferating cells started to resuscitate within an hour in fresh media after the removal of ampicillin and arsenate (Fig. 6b, the cell subpopulations highlighted with light-green circles), and reached the stationary phase very quickly (Fig. $6 \mathrm{~b}, \mathrm{t}=240 \mathrm{~min}$ and Additional file 1: Fig. S8). We note that the cultures at $\mathrm{t}=$ 240 min were further diluted for flow-cytometry analysis; this explains the reduction in the number of non-growing cells shown in the flow diagram (Fig. $6 \mathrm{~b}, \mathrm{t}=240 \mathrm{~min}$ and Additional file 1: Fig. S8). Due to their transition to the stationary phase, FSC of resuscitating cells decreased at $\mathrm{t}=240 \mathrm{~min}$ (Fig. 6b). This is expected as the reductive division resulting in small spherical cells is known to take place when cells enter the stationary phase [19]. We also note that the chromosomal mCherry expression cassette is slightly leaky during the stationary phase even in the absence of IPTG; therefore, mCherry levels of resuscitated cells at $t=240 \mathrm{~min}$ (Fig. 6b) are slightly higher than expected. This might be due to the up-regulation of CRP/ cAMP complex during the stationary phase, as this complex tightly regulates the lac promoters. However, this phenomenon does not impact our current analysis; therefore, we are not planning to investigate this further. The control group has undergone similar procedures without receiving any arsenate treatment. All proliferating cells were lysed by ampicillin, and only a small fraction of intact cells from the non-growing cell subpopulation was able to resuscitate in the control group (Fig. 6a), consistent with our aforementioned results.

Antibiotic treatments have been performed in the presence of arsenate in previous studies [21, 22], which makes it ambiguous whether the arsenate-induced persistence is indeed due to the ATP depletion. To figure out this, we performed the persister assays mentioned above in the absence of arsenate. After the pretreatment with arsenate, we washed the cells with Phosphate Buffered Saline (PBS) solution to remove the chemical and transferred the washed cells to fresh media with ampicillin. This washing procedure did not affect the exponential-phase persister (Figs. 6c vs. 7c) and ATP levels (Figs. 6d vs. 7d) in control groups. Our flow

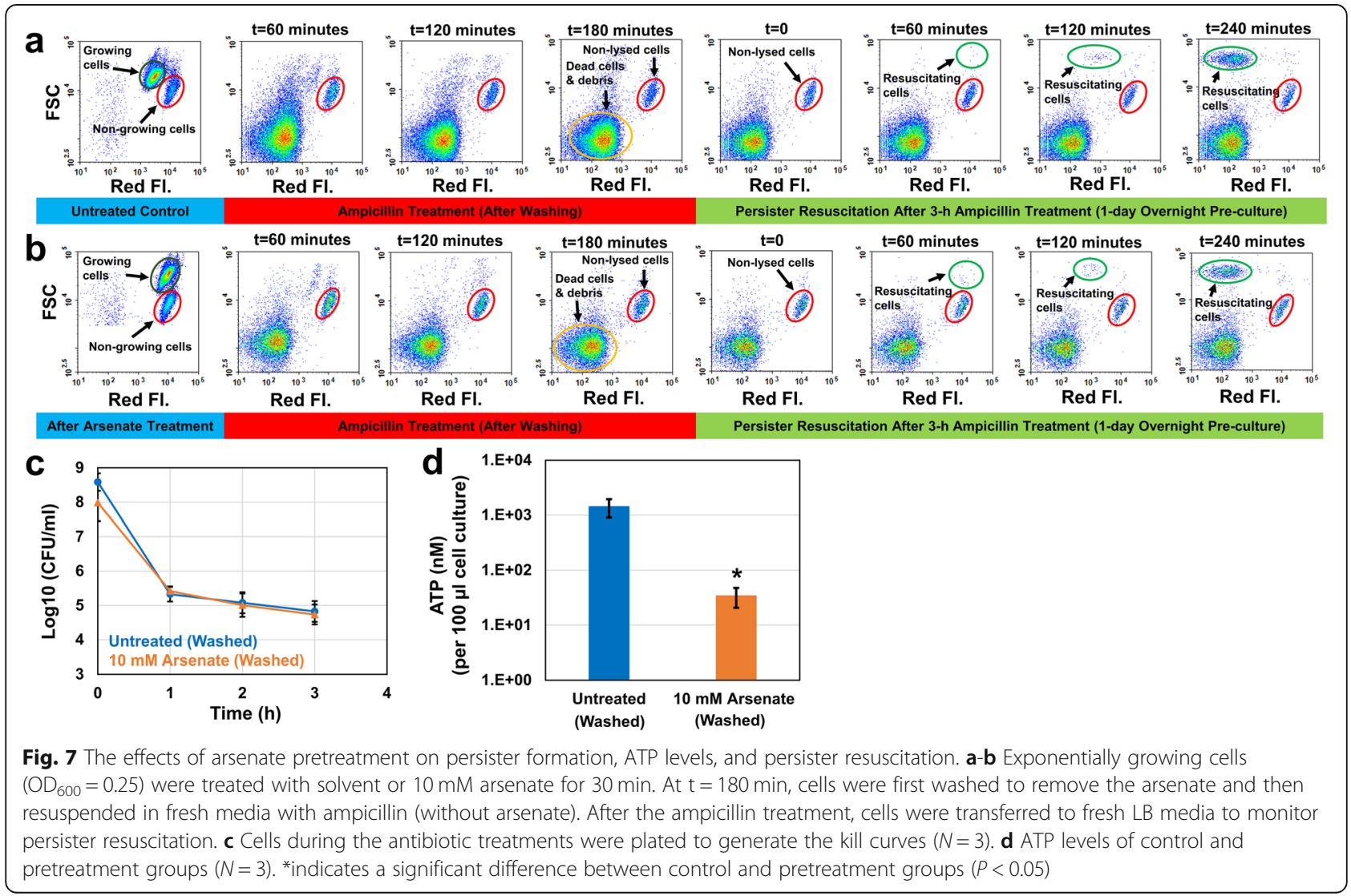


cytometry analysis showed that growing subpopulations in both pretreatment and control groups were lysed within $3 \mathrm{~h}$ by ampicillin (Fig. 7a,b). Unexpectedly, both groups have similar persister levels (Fig. 7c), despite the significant reduction in ATP levels observed in arsenatepretreated cultures (Fig. 7d). Also, persisters from nongrowing cell subpopulations started to resuscitate within an hour in both pretreatment and control groups when they were exposed to fresh media (Fig. 7a,b). Overall, these results indicate that the ATP-depleted cultures do not necessarily exhibit increased persistence (Fig. 7c); in fact, the enhanced persistence shown in Fig. $6 \mathrm{c}$ is potentially due to the synergistic effect of arsenate in cotreated cultures.

\section{Discussion}

In this study, we presented an exploratory methodology, incorporating the flow cytometer with cells expressing a fluorescent indicator of cell division, to monitor resuscitating cells after antibiotic treatments. We used ampicillin for our assays, which is commonly used to isolate persister populations $[10,12]$, given its ability to lyse the proliferating cells $[15,16]$. We have demonstrated that only a small fraction of non-lysed cell populations wakes up, and this phenomenon has been observed within 1 hour (independent of pre-culturing and treatment times) after transferring the antibiotic-treated cells to fresh liquid media.

Using a microfluidic device, Windels and coworkers have shown that persister resuscitation is stochastic and resuscitation time ranges from a few minutes to $13 \mathrm{~h}$, with $30-40 \%$ cells dividing within 1 hour [25]. We note that culture conditions, treatment times and the antibiotic used in our study are significantly different than those in the study of Windels and coworkers. Here, we transferred antibiotic-treated cells to fresh, rich media in baffled flasks and cultured with shaking. These culture conditions are known to promote cell growth [26, 27]. It is possible that the rapid overpopulation of progenies originating from the early-dividing cells might have prevented the growth of other resuscitating cells emerging at later time points. This might also explain why the nongrowing cells characterized by lower FSC in arsenate treated cultures shown in Fig. 6b did not go through the same resuscitation process as in the other conditions. Unfortunately, growing cells were not lysed by ampicillin in the presence of arsenate and these cells reached the stationary phase quickly upon their resuscitation after the removal of the chemicals (Fig. 6b).

Recurrent and chronic infections are generally associated with biofilms where persister cells are significantly enriched and evade the host immune system. Although some persistent infections are associated with clinically apparent-chronic symptoms, some cases are asymptomatic for a long time [28]. Given that antibiotics can diffuse through biofilms [29], the concept of a "protected niche" is not enough to explain the prolonged survival of microorganisms in the human body [28]. In fact, this can be explained by the "adaptive plasticity" of bacteria, i.e. the ability of bacteria to "play dead", suggested by Walsh McDermott in 1958 [30]. This hypothesis has been supported by many studies clearly demonstrating that bacteria causing recurrent infections can be present within the host in a non-replicating or slowly replicating state that cannot be easily cultured in vitro [31]. Lleo and coworkers reported that $14 \%$ of clinical samples from 182 patients, which did not form bacterial colonies on standard media, had VBNCs [32]. Since both VBNCs and persisters are concurrently present in cell cultures [12] and capable of continued pathogenesis in host organisms [28], the simultaneous characterization of these two phenotypes is essential. Unfortunately, studies characterizing persister cell physiology rarely focused on VBNC cells. A few research groups have already verified that there are many more VBNC cells than persisters in antibiotic-treated cultures $[8,9]$. Using live/dead staining and water-soluble tetrazolium salt dye, we demonstrated that these VBNC cells are indeed live cells with the ability to efficiently metabolize certain carbon sources [12].

In our study, we showed that long-term (9 days) pre cultures have $\sim 3-4$ fold more VBNC cells compared to short-term (1 day) pre-cultures. We note that stresses associated with stationary-phase cultures, such as nutrient starvation, oxidative stress, $\mathrm{pH}$ change and toxic waste from starved cells are already known to induce VBNC cell formation [31, 33-36]. Another interesting observation is related to resuscitating cell levels determined from the standard plating method and flow-cytometry analysis. Although antibiotic treatment or pre-culturing times have minimal effects on persister wake-up and doubling times in liquid cultures, the number of persisters resuscitating on agar plates was found to be significantly lower than that of liquid cultures when we used 9-day pre-cultures. The culturability of VBNC cells is already known to depend on the culture conditions [37]. Reduced resuscitation of VBNC cells can be observed on agar media compared to liquid cultures due to the impurity of agar, cell density and restricted diffusion of nutrients [37]. The oxidative stress on agar media was also shown to inhibit the resuscitation of VBNC cells [14].

Energy metabolism was shown to be inversely correlated with persistence in previous studies [21-23, 3840], where exponential-phase cultures were generally treated with a metabolic inhibitor, such as arsenate. Shan et al. have shown that the reduction in intracellular ATP concentration led to the inactivation of the 
antibiotic target site [22]. They treated exponentially growing E. coli cells with arsenate for half an hour followed by ampicillin treatment and observed a significant increase in persister levels [22]. Braetz et al. have found a similar mechanism in Salmonella strains [40]. They reported a significant increase in ciprofloxacin persisters in arsenate-treated cell cultures [40]. Unfortunately, persister assays in these studies were performed in the presence of arsenate, which may not eliminate the synergistic effects of co-treatments.

\section{Conclusions}

In summary, we presented here a methodology that aims to monitor persister resuscitation. This method also enables us to quantify non-resuscitating cells (VBNCs), which are generally ignored by the persister research community, despite certain phenotypic similarities between these cells and persisters. We believe that this approach will provide a platform to study persistence and VBNC state that can be expanded to different antibiotics and organisms. This experimental approach can also be used to isolate resuscitating cells using cell sorting instruments to directly assess their physiological characteristics with conventional methodologies (e.g., genomics, proteomics, and metabolomics) to fill a fundamental knowledge gap within our understanding of persister physiology.

\section{Methods}

\section{Bacterial strains and plasmids}

Escherichia coli MG1655 MO strain and pQE-80 L plasmids harboring genes encoding a green fluorescent protein (GFP) were previously generated $[8,41,42]$. E. coli MO strain harbors a chromosomally integrated IPTGinducible $m$ Cherry expression cassette $[8,42]$, which is used to monitor cell proliferation at the single cell level. pQE-80 L expression system has a kanamycin resistance gene $\left(\mathrm{kan}^{R}\right)$ with an IPTG-inducible synthetic T5 promoter and a strong constitutive LacI $^{q}$ promoter as a repressor, to tightly regulate the expression of GFP [41].

\section{Media, chemicals, and culture conditions}

All chemicals were purchased from Fisher Scientific (Atlanta, GA), VWR International (Pittsburg, PA) or Sigma Aldrich (St. Louis, MO). LB liquid media prepared from its components ( $5 \mathrm{~g}$ yeast extract, $10 \mathrm{~g}$ tryptone and $10 \mathrm{~g}$ sodium chloride in $1 \mathrm{~L}$ ultra-pure DI water) [41, 43]. LB agar media ( $40 \mathrm{~g}$ premixed LB agar in $1 \mathrm{~L}$ ultra-pure DI water) was used to enumerate CFUs. Cells were washed with PBS solution to remove the antibiotics. For persister assays, $60 \mu \mathrm{g} / \mathrm{ml}$ (10X of MIC) ampicillin was used. To determine the MIC of ampicillin, cells were cultured in $2 \mathrm{ml} \mathrm{LB}$ media in $14 \mathrm{ml}$ round bottom falcon tubes where the antibiotic was serially diluted (2-fold) [43, 44].
The MIC range of ampicillin for E. coli MG1655 MO is $3.125-6.25 \mu \mathrm{g} / \mathrm{ml}$ [43]. Kanamycin $(50 \mu \mathrm{g} / \mathrm{ml})$ was added to the culture media for the selection and retention of plasmids. IPTG $(1 \mathrm{mM})$ was used to induce mCherry and GFP expression [41]. Overnight pre-cultures were prepared by inoculating frozen cells $\left(-80^{\circ} \mathrm{C}\right)$ in $2 \mathrm{ml} \mathrm{LB}$ broth in a $14 \mathrm{ml}$ round bottom falcon tube and grown for $24 \mathrm{~h}$ or more (up to 9 days) at $37^{\circ} \mathrm{C}$ with shaking (250 rpm). IPTG $(1 \mathrm{mM})$ was added if the expression of fluorescent proteins was required.

\section{Persister assays}

Overnight pre-cultures of E. coli MG1655 MO cells were diluted 100-fold into $25 \mathrm{ml} \mathrm{LB}$ media in 250-ml baffled flasks and grown in the presence of $1 \mathrm{mM}$ IPTG (to induce mCherry) at $37^{\circ} \mathrm{C}$ with shaking $(250 \mathrm{rpm})$. We note that, depending on the overnight pre-culture lengths, the inoculation rates were adjusted to transfer the same amount of pre-culture cells to the media. When the cell density reached $\mathrm{OD}_{600}=0.25$ at $\mathrm{t}=150$ min (cell count $\sim 10^{8}$ cells $/ \mathrm{ml}$ ), cultures were treated with ampicillin at $37^{\circ} \mathrm{C}$ with shaking. At designated time points, $t=0$ (right before the antibiotic treatment), 1, 2, 3 and $16 \mathrm{~h}, 1 \mathrm{ml}$ samples were collected and centrifuged at 13,300 rpm for $3 \mathrm{~min}$ to pellet the cells. After centrifugation, $950 \mu \mathrm{l}$ of supernatant was removed from each microcentrifuge tube, and $950 \mu \mathrm{l}$ of PBS was then added to resuspend the cells. This procedure was repeated at least twice to dilute the antibiotics to sub-MIC levels. After washing, cells were serially diluted in PBS using round-bottom 96-well plates, and, then, $10 \mu \mathrm{l}$ of cell suspensions were spotted on LB agar. The agar plates were incubated at $37^{\circ} \mathrm{C}$ for $16 \mathrm{~h}$ to enumerate the CFUs. We note that new colonies were not formed when incubated beyond $16 \mathrm{~h}$.

\section{Monitoring persister resuscitation with a flow cytometer}

Entire cultures of E. coli MG1655 MO cells, treated with ampicillin as described above, were collected at indicated time points $(3 \mathrm{~h}$ or $16 \mathrm{~h}$ ) and pelleted in $50 \mathrm{ml}$ falcon tubes by centrifuging at $4700 \mathrm{rpm}$ for $15 \mathrm{~min}$. The pelleted cells were then suspended in $1 \mathrm{ml}$ PBS and transferred to microcentrifuge tubes. After washing with PBS to remove the antibiotic and IPTG completely, the cells were inoculated in $25 \mathrm{ml}$ fresh LB media in $250 \mathrm{ml}$ baffled flasks and incubated at $37^{\circ} \mathrm{C}$ with shaking in the absence of IPTG. Every $30 \mathrm{~min}, 200 \mu \mathrm{l}$ cell cultures were collected from the flasks and diluted in $800 \mu \mathrm{l}$ PBS solution and immediately analyzed with a flow cytometer to measure the mCherry levels of resuscitating cells (NovoCyte Flow Cytometer, NovoCyte 3000RYB, ACEA Biosciences Inc., San Diego, CA).

To verify that resuscitating cells are live and capable of expressing proteins, we used E. coli MG1655 strain with 
pQE-80 L plasmids harboring IPTG inducible $g f p$. The cells were grown and treated with ampicillin as described above but without IPTG. The inducer $(1 \mathrm{mM})$ was added after transferring the antibiotic-treated cells to fresh media. Resuscitating cells expressing GFP was monitored with the flow cytometer. Cells carrying empty vectors served as a negative control. All samples were assayed with lasers emitting at $488 \mathrm{~nm}$ for GFP or 561 $\mathrm{nm}$ for mCherry. Fluorescence was collected by 530/30 $\mathrm{nm}$ bandpass filter for GFP and $615 / 20 \mathrm{~nm}$ bandpass filter for mCherry. In each run, we measured 60,000 events. Sterile PBS, wild-type (WT) E. coli, mCherrypositive and GFP-positive cells were used to gate the cell populations on flow-cytometry diagrams. Cells were counted using the volumetric-based cell counting feature of the NovoCyte Flow Cytometer; this enabled us to calculate the growing, non-growing, non-lysed or resuscitating cell levels in cultures after taking dilution factors into consideration.

\section{Persister cell growth and doubling time quantification}

In the absence of IPTG, mCherry concentration in growing cells was reduced with time due to the cell division. Because of this correlation, the red fluorescence reduction with the culture time was used to calculate the celldoubling time with the following fluorescence decay equation:

$$
F=F_{0} 2^{-\left(t-t_{o}\right) / t_{d}}
$$

where $F_{0}$ is the mean fluorescence intensity of the resuscitating cell population at $t_{o} ; t_{d}$ is the doubling time; and $\mathrm{F}$ is the mean fluorescence intensity of resuscitating cell population at time $t$. Fluorescent measurements of dividing cells were performed with a flow cytometer as described above. Since we were able to measure the mean fluorescence intensity of resuscitating cells around 60 min after transferring the antibiotic-treated cells to fresh media, $t_{o}$ was chosen to be $60 \mathrm{~min}$. Excel SOLVER was used to calculate doubling time by minimizing the sum of normalized mean square errors (NMSE) between experimental and predicted model data.

To calculate the initial number of persister cells that resuscitated, the classical doubling time formula for the exponential-growth phase was used:

$$
N=N_{o} 2^{\left(t-t_{o}\right) / t_{d}}
$$

where $\mathrm{N}_{\mathrm{o}}$ is the initial number of cells that started to resuscitate at $t_{0} ; t_{d}$ is the doubling time of that particular experimental condition and calculated from the fluorescence decay equation as described above. $\mathrm{N}$ is the number of resuscitated cells that were counted at time t. The flow-cytometry cell counts obtained at $\mathrm{t}=240 \mathrm{~min}$ were used for $\mathrm{N}$. $\mathrm{N}_{\mathrm{o}}$ levels were calculated from the exponential growth equation using two different scenarios: $\mathrm{t}_{\mathrm{o}}=0$ and $\mathrm{t}_{\mathrm{o}}=60 \mathrm{~min}$.

\section{Arsenate pretreatment}

Overnight pre-cultures of E. coli MG1655 MO cells were diluted 100-fold into $25 \mathrm{ml} \mathrm{LB}$ media in $250-\mathrm{ml}$ baffled flasks and grown as described above. When the cell density reached $\mathrm{OD}_{600}=0.25(\mathrm{t}=150 \mathrm{~min})$, cultures were treated with $10 \mathrm{mM}$ arsenate (sodium hydrogen arsenate heptahydrate, Fisher Scientific, catalog\# AAA1827522) for $30 \mathrm{~min}$ at $37^{\circ} \mathrm{C}$ with shaking ( $250 \mathrm{rpm}$ ). At $\mathrm{t}=180$ $\mathrm{min}$, the arsenate-pretreated cells were challenged with ampicillin $(60 \mu \mathrm{g} / \mathrm{ml}, 10 \mathrm{X}$ of $\mathrm{MIC})$ for $3 \mathrm{~h}$. Persister quantification at designated time points was performed as described above. We note that, when necessary, cells were washed with PBS to remove the arsenate and suspended into $25 \mathrm{ml} \mathrm{LB}$ media in 250-ml baffled flasks followed by the ampicillin treatments. Control groups, treated with solvent only (DI water), have undergone the same procedures.

\section{ATP measurements}

The intracellular ATP levels of control and treatment (arsenate) groups were measured using a BacTiter-Glo ${ }^{\mathrm{mm}}$ Microbial Cell Viability Assay kit (Catalog\# G8230, Promega Corporation, Madison, WI) according to manufacturer's guideline. Fresh LB media was used to measure the background luminescence. Standard curves were generated by measuring the luminescence of ATP solutions at known concentrations. These solutions were prepared by serially diluting rATP (Promega catalog\# P1132) in fresh LB.

\section{Statistical analysis}

In this study, at least three independent biological replicates were performed for each condition. Two-tailed student $\mathrm{t}$-test with unequal variance was used to determine statistical significance where the threshold $P$-value is 0.05 [41]. All $t_{d}$ or $N_{o}$ calculations were performed for each biological replicate. Each experimental or computational data point in the figures represents mean value \pm standard deviation.

\section{Supplementary information}

Supplementary information accompanies this paper at https://doi.org/10. 1186/s12866-020-01888-3.

\footnotetext{
Additional file 1: Fig. S1. Cell growth of E. coli MG1655 MO strain in LB broth medium. (A) mCherry positive cells from 1-day overnight precultures were diluted 100-fold in fresh media and grown in the absence of IPTG. At designated time points, samples were collected to monitor the proliferating cells with a flow cytometer $(N=4)$. (B) The doubling time of the resuscitating cells was calculated using the decay equation (see the Materials and Methods) and the mean fluorescence intensities of dividing cells (highlighted with dark-green circles) $(N=4)$. Fig. S2. The comparison of calculated and experimentally quantified resuscitating cell
} 
levels. (A) Cells from overnight (1 day) pre-cultures were diluted (100-fold) in fresh media, cultured to mid-exponential phase $(\mathrm{OD} 600=0.25)$ and then treated with ampicillin $(60 \mu \mathrm{g} / \mathrm{ml})$ for $3 \mathrm{~h}$. After the treatment, cells were transferred to fresh media and cultured to count the resuscitating cells at $\mathrm{t}=60 \mathrm{~min}$ with a flow cytometer. The resuscitating cells were also calculated using the classical exponential growth equation as described in the main text. (B) The similar experimental procedures were performed as described in A. Cells were obtained from 1-day overnight pre-cultures; however, persister assays were performed for $16 \mathrm{~h}$. (C) Cells were obtained from 9-day overnight pre-cultures, and persister assays were performed for 3 h. (D) Cells were obtained from 9-day overnight precultures, and persister assays were performed for $16 \mathrm{~h}$. Fig. $\mathbf{S 3}$. Monitoring persister resuscitation with a GFP expression system. (A-B) Stationary-phase cultures of $E$. coli cells harboring pQE-80 L empty vector (EV) or pQE-80 L::gfp were inoculated (1:100) into fresh media and cultured without IPTG. Upon reaching the mid-exponential growth phase $(\mathrm{OD} 600=0.25)$, cells were treated with $60 \mu \mathrm{g} / \mathrm{ml}$ ampicillin for $3 \mathrm{~h}$. Cells were then washed to remove the antibiotic and resuspended in fresh media with IPTG. At designated time points samples were collected and analyzed with a flow cytometry. As expected, resuscitating cells (highlighted with green circles), exhibiting higher forward side scatter (FCS) signals due to the elongation characteristic of growing cells, were able to express GFP. (C) Resuscitating-cell growth was monitored by measuring the GFP positive cells with a flow cytometer. It was also monitored using the mCherry dilution method as described in Fig. 2 in the main text. Although we did not observe a significant difference between the results of these two methods, over-expressing GFP with high-copy plasmids slightly reduced cell growth, an expected observation. Green Fl:: Green Fluorescence. Fig. S4. VBNC levels in shortand long-term ampicillin treatments. Viable but non-culturable (VBNC) cells were determined by subtracting the number of persisters (agar plate data) from non-growing cells (flow cytometry data) $(N=4)$. Fig. S5. The effect of long-term pre-culturing on persister resuscitation. To test the stationary-phase lengths on persister resuscitation, overnight pre-cultures were cultured up to 9 days. On certain days (A: 2-day, B: 3-day, C: 5-day, and D: 7-day), cells were inoculated (1:100-fold) in fresh media in the presence of IPTG and cultured until the mid-exponential-growth phase $(\mathrm{OD} 600=0.25)$ was obtained. Then, cells were treated with $60 \mu \mathrm{g} / \mathrm{ml}$ ampicillin. Three hours after the treatment, cells were transferred to fresh media to monitor persister resuscitation at indicated time points. Note that the data corresponding to 9-day overnight cultures was provided in the main text. Fig. S6. The effect of long-term pre-culturing on persister resuscitation. Cells were grown the same way as described in Fig. S5; however, the ampicillin treatment was performed for $16 \mathrm{~h}$. A: 2-day, B: 3day, C: 5-day, and D: 7-day. Fig. S7. mCherry levels in the stationary phase cells obtained from 1-day or 9-day overnight pre-cultures. mCherry levels were measured with a flow cytometer $(N=4)$. Protein degradation/ leakage is known to be observed in long-term cultures. Fig. S8. Resuscitation of cells after arsenate and ampicillin treatment. Arsenate and ampicillin treated cells were washed and inoculated in fresh LB media to monitor the persister resuscitation. Samples were analyzed with flow cytometer every $30 \mathrm{~min}(\mathrm{~N}=3)$. Table S1. Estimating the doubling times of resuscitating cells using the cell counts or mCherry dilution method. ONC=Overnight pre-culture.

\section{Abbreviations}

VBNC: Viable but non-culturable; ATP: Adenosine triphosphate; IPTG: Isopropyl $\beta$-D-1-thiogalactopyranoside; FSC: Forward scatter; OD6 ${ }_{00}$ : Optical density at $600 \mathrm{~nm}$ wavelength; CFU: Colony forming unit; GFP: Green fluorescence protein; CAMP: Cyclic adenosine monophosphate; CRP: CAMP receptor protein; PBS: Phosphate buffered saline; MIC: Minimum inhibitory concentration; NMSE: Normalized mean square errors; Kan: Kanamycin

\section{Acknowledgements}

We would like to thank the members of Orman Lab for their valuable contributions for this research project.

\section{Authors' contributions}

S.G.M, P.K. and M.A.O. conceived and designed the study. S.G.M and P.K. performed the experiments. S.G.M., P.K. and M.A.O. analyzed the data and wrote the paper. All authors have read and approved the manuscript.

\section{Funding}

The research was supported by NIH/NIAID K22Al125468 Career Transition Award, NIH/NIAID R01-Al143643-01A1 Award, and University of Houston start-up grant. The funding sources had no role in the design of the study and collection, analysis, and interpretation of data and in writing the manuscript.

\section{Availability of data and materials}

Data provided in this paper including supplementary materials are sufficient to assess the findings of this paper. Additional data of this paper can be obtained upon request.

\section{Ethics approval and consent to participate}

Not applicable.

\section{Consent for publication}

Not Applicable.

\section{Competing interests}

The authors declare no competing interests.

Received: 2 April 2020 Accepted: 29 June 2020

Published online: 08 July 2020

\section{References}

1. Van den Bergh B, Fauvart M, Michiels J. Formation, physiology, ecology, evolution and clinical importance of bacterial persisters. FEMS Microbiol Rev. 2017:41:219-51.

2. Gerdes K, Maisonneuve E. Bacterial persistence and toxin-antitoxin loci. Annu Rev Microbiol. 2012;66:103-23. https://doi.org/10.1146/annurev-micro092611-150159.

3. Luidalepp H, Jõers A, Kaldalu N, Tenson T. Age of inoculum strongly influences persister frequency and can mask effects of mutations implicated in altered persistence. J Bacteriol. 2011;193:3598-605.

4. Meylan S, Andrews IW, Collins JJ. Targeting antibiotic tolerance, pathogen by Pathogen. Cell. 2018;172:1228-38.

5. Lewis K. Persister cells, dormancy and infectious disease. Nat Rev Microbiol. 2007:5:48-56

6. Wood TK, Knabel SJ, Kwan BW. Bacterial persister cell formation and dormancy. Appl Environ Microbiol. 2013;79:7116-21.

7. Shah D, Zhang Z, Khodursky A, Kaldalu N, Kurg K, Lewis K. Persisters: A distinct physiological state of E. coli. BMC Microbiol. 2006;6:53. https://doi. org/10.1186/1471-2180-6-53.

8. Orman MA, Brynildsen MP. Dormancy is not necessary or sufficient for bacterial persistence. Antimicrob Agents Chemother. 2013;57:3230-9.

9. Roostalu J, Jõers A, Luidalepp H, Kaldalu N, Tenson T. Cell division in Escherichia coli cultures monitored at single cell resolution. BMC Microbiol. 2008;8:68

10. Keren I, Shah D, Spoering A, Kaldalu N, Lewis K. Specialized persister cells and the mechanism of multidrug tolerance in Escherichia coli. J Bacteriol. 2004;186:8172-80

11. Cañas-Duarte SJ, Restrepo S, Pedraza JM. Novel Protocol for Persister Cells Isolation. PLoS ONE. 2014;9(2):e88660. https://doi.org/10.1371/journal.pone. 0088660.

12. Orman MA, Brynildsen MP. Establishment of a method to rapidly assay bacterial persister metabolism. Antimicrob Agents Chemother. 2013:57: 4398-409.

13. Ayrapetyan M, Williams TC, Oliver JD. Bridging the gap between viable but non-culturable and antibiotic persistent bacteria. Trends Microbiol. 2015;23: $7-13$

14. Kong IS, Bates TC, Hülsmann A, Hassan H, Smith BE, Oliver JD. Role of catalase and oxyR in the viable but nonculturable state of Vibrio vulnificus. FEMS Microbiol Eco. 2004;50(3):133-42. https://doi.org/10.1016/j.femsec.2004. 06.004. 
15. Cho H, Uehara T, Bernhardt TG. Beta-lactam antibiotics induce a lethal malfunctioning of the bacterial cell wall synthesis machinery. Cell. 2014;159: $1300-11$.

16. Lee AJ, Wang S, Meredith HR, Zhuang B, Dai Z, You L. Robust, linear correlations between growth rates and $\beta$-lactam-mediated lysis rates. Proc Natl Acad Sci U S A. 2018;115:4069-74.

17. Dörr T, Lewis K, Vulić M. SOS Response Induces Persistence to Fluoroquinolones in Escherichia coli. PLoS Genet. 2009;5(12):e1000760. https://doi.org/10.1371/journal.pgen.1000760.

18. Balaban NQ, Merrin J, Chait R, Kowalik L, Leibler S. Bacterial persistence as a phenotypic switch. Science. 2004;305:1622-5.

19. Nyström T. Stationary-Phase Physiology. Annu Rev Microbiol. 2004;58:161-81.

20. Navarro Llorens JM, Tormo A, Martínez-García E. Stationary phase in gramnegative bacteria. FEMS Microbiol Rev. 2010;34:476-95. https://doi.org/10. 1111/j.1574-6976.2010.00213.x.

21. Conlon BP, Rowe SE, Gandt AB, Nuxoll AS, Donegan NP, Zalis EA, et al. Persister formation in Staphylococcus aureus is associated with ATP depletion. Nat Microbiol. 2016;1:1-7.

22. Shan Y, Brown Gandt A, Rowe SE, Deisinger JP, Conlon BP, Lewis K. ATPdependent persister formation in Escherichia coli. mBio. 2017;8:e02267-16. https://doi.org/10.1128/mBio.02267-16.

23. Cameron DR, Shan Y, Zalis EA, Isabella V, Lewis K. A genetic determinant of persister cell formation in bacterial pathogens. J Bacteriol. 2018;200:e0030318. https://doi.org/10.1128/JB.00303-18.

24. Wolfe-Simon F, Blum JS, Kulp TR, Gordon GW, Hoeft SE, Pett-Ridge J, et al. A bacterium that can grow by using arsenic instead of phosphorus. Science. 2011;332:1163-6.

25. Windels EM, Ben Meriem Z, Zahir T, Verstrepen KJ, Hersen P, Van den Bergh $B$, et al. Enrichment of persisters enabled by a B-lactam-induced filamentation method reveals their stochastic single-cell awakening. Commun Biol. 2019;2:1-7.

26. Sezonov G, Joseleau-Petit D, D'Ari R. Escherichia coli physiology in LuriaBertani broth. J Bacteriol. 2007;189:8746-9.

27. Büchs, J. Introduction to advantages and problems of shaken cultures. Biochemical Engineering Journal. 2001;7(2):91-8. https://doi.org/10.1016/ S1369-703X(00)00106-6.

28. Grant SS, Hung DT. Persistent bacterial infections, antibiotic tolerance, and the oxidative stress response. Virulence. 2013;4:273-83.

29. Anderl JN, Franklin MJ, Stewart PS. Role of antibiotic penetration limitation in Klebsiella pneumoniae biofilm resistance to ampicillin and ciprofloxacin. Antimicrob Agents Chemother. 2000;44:1818-24.

30. McDERMOTT W. Microbial persistence. Yale J Biol Med. 1958;30:257-91.

31. Colwell RR. Viable but nonculturable bacteria: A survival strategy. J Infect Chemother. 2000;6:121-5.

32. Lleo MM, Ghidini V, Tafi MC, Castellani F, Trento I, Boaretti M. Detecting the presence of bacterial DNA by PCR can be useful in diagnosing culturenegative cases of infection, especially in patients with suspected infection and antibiotic therapy. FEMS Microbiol Lett. 2014;354:153-60. https://doi. org/10.1111/1574-6968.12422.

33. Na SH, Miyanaga K, Unno H, Tanji Y. The survival response of Escherichia coli K12 in a natural environment. Appl Microbiol Biotechnol. 2006;72:386-92.

34. Cook KL, Bolster CH. Survival of campylobacter jejuni and Escherichia coli in groundwater during prolonged starvation at low temperatures. J Appl Microbiol. 2007;103:573-83. https://doi.org/10.1111/j.1365-2672.2006.03285.x.

35. Kolter $\mathrm{R}$, Siegele DA, Tormo A. The stationary phase of the bacterial life cycle. Annu Rev Microbiol. 1993;47:855-74. https://doi.org/10.1146/annurev. mi.47.100193.004231.

36. Dukan S, Nyström T. Oxidative stress defense and deterioration of growtharrested Escherichia coli cells. J Biol Chem. 1999;274:26027-32.

37. Wai SN, Mizunoe Y, Takade A, Yoshida SI. A comparison of solid and liquid media for resuscitation of starvation- and low-temperature-induced nonculturable cells of Aeromonas hydrophila. Arch Microbiol. 2000;173:307-10.

38. Kwan BW, Valenta JA, Benedik MJ, Wood TK. Arrested protein synthesis increases persister-like cell formation. Antimicrob Agents Chemother. 2013; 57:1468-73.

39. Cui P, Niu H, Shi W, Zhang S, Zhang W, Zhang Y. Identification of Genes Involved in Bacteriostatic Antibiotic-Induced Persister Formation. Front Microbiol. 2018;9:MAR:413. https://doi.org/10.3389/fmicb.2018.00413.

40. Braetz S, Schwerk P, Thompson A, Tedin K, Fulde M. The role of ATP pools in persister cell formation in (fluoro)quinolone-susceptible and -resistant strains of Salmonella enterica ser. Typhimurium. Vet Microbiol. 2017;210:116-23.
41. Orman MA, Brynildsen MP. Inhibition of stationary phase respiration impairs persister formation in E. coli. Nat Commun. 2015;6:1-13.

42. Mok WWK, Park JO, Rabinowitz JD, Brynildsen MP. RNA futile cycling in model persisters derived from MazF accumulation. mBio. 2015;6(6):e0158815. https://doi.org/10.1128/mBio.01588-15.

43. Mohiuddin SG, Hoang T, Saba A, Karki P, Orman MA. Identifying metabolic inhibitors to reduce bacterial persistence. Front Microbiol. 2020;11:472. https://doi.org/10.3389/fmicb.2020.00472.

44. Andrews JM. Determination of minimum inhibitory concentrations. J Antimicrob Chemother. 2001;48(suppl_1):5-16. https://doi.org/10.1093/jac/ 48.suppl_1.5.

\section{Publisher's Note}

Springer Nature remains neutral with regard to jurisdictional claims in published maps and institutional affiliations.
Ready to submit your research? Choose BMC and benefit from:

- fast, convenient online submission

- thorough peer review by experienced researchers in your field

- rapid publication on acceptance

- support for research data, including large and complex data types

- gold Open Access which fosters wider collaboration and increased citations

- maximum visibility for your research: over $100 \mathrm{M}$ website views per year

At BMC, research is always in progress.

Learn more biomedcentral.com/submissions 